\title{
Rectal aminophylline in the management of apnoea of prematurity
}

\author{
A J LYON AND N McINTOSH \\ Neonatal Unit, St George's Hospital, London
}

SUMMARY Rectal suppositories as an alternative to intravenous aminophylline in the management of recurrent apnoea were studied in 41 preterm infants of mean gestation 28.3 weeks and mean birthweight $1176 \mathrm{~g}$. Therapeutic blood concentrations were obtained two hours after a rectal loading dose of $10 \mathrm{mg} / \mathrm{kg}$, with steady concentrations and maximum reduction in apnoeic episodes (from a mean of 0.5 per hour to 0.09 per hour) within 24 hours on a maintenance dose of $10 \mathrm{mg} / \mathrm{kg} /$ day. There was good correlation between the rectal dose and the plasma theophylline concentration. Several infants showed a significant reduction in $\mathrm{PcO}_{2}$ when treated with aminophylline. Side effects were related to the plasma theophylline concentration and were not seen at concentrations less than $14 \mathrm{mg} / \mathrm{l}$.

Methylxanthines are effective in the managment of apnoea of prematurity. ${ }^{12}$ Dosage schedules for intravenous aminophylline have been reported, ${ }^{34}$ but repeated venous access can be a problem in the preterm neonate if no intravenous line is in situ. Oral preparations are absorbed erratically and have possible gastrointestinal side effects. ${ }^{3}$

There have been reports of unpredictable blood concentrations and deaths in children and adults using aminophylline suppositories in the treatment of asthma. ${ }^{56}$ In the apnoeic neonate, however, aminophylline suppositories have been effective, ${ }^{17}$ but neither blood concentrations nor any assessment of toxic effects have been reported.

The policy at this hospital has been to use an intravenous loading dose of aminophylline followed by maintenance treatment with suppositories. The intravenous dose has often been omitted, however, if no intravenous line has been available.

This study aimed to evaluate clinical experience with aminophylline suppositories in the management of apnoea of prematurity and to obtain pharmacokinetic data for this preparation. In particular, suppositories were compared with intravenous aminophylline as an effective means of administering a loading dose of theophylline.

\section{Patients and methods}

To determine the optimum maintenance dose of rectal aminophylline the plasma theophylline concentrations achieved in 40 infants on varying doses were obtained retrospectively from hospital notes; all concentrations were determined after the baby had been on aminophylline for at least 48 hours. The concentrations were plotted against dose and the regression line calculated by the method of least squares.

Forty one preterm infants (gestation, mean (SD) 28.3 (2.2) weeks; birthweight, mean (SD) 1176 $(350 \mathrm{~g})$ ) with recurrent apnoea, defined as cessation of respiration for 20 seconds with associated bradycardia or cyanosis, were then studied prospectively.

Three groups of similar gestation, birthweight, and age at start of treatment were compared:

(a) No loading dose $(n=17)$.

(b) Rectal loading dose $10 \mathrm{mg} / \mathrm{kg} \quad(\mathrm{n}=12)$.

(c) Intravenous' loading dose $6 \mathrm{mg} / \mathrm{kg})(\mathrm{n}=12)$.

Starting four hours after the loading dose, maintenance treatment in all three groups was with aminophylline suppositories (Macarthy Ltd), 10 $\mathrm{mg} / \mathrm{kg} / \mathrm{day}$ in three or four divided doses. The suppositories were held in the rectum by a finger over the anus until dissolved, usually in one to two minutes.

Theophylline concentrations in plasma were determined using an enzyme multiplied immunoassay technique (EMIT, SYVA Chemicals). Blood (0.5 $\mathrm{ml}$ ) for plasma theophylline determinations was taken at one, two, and three hours after the loading dose, before maintenance treatment had begun, and then at 24 hours and 48 hours after starting this. Plasma concentrations were checked further, as necessary, for therapeutic monitoring, the dose 
being altered to keep the concentrations between 6 and $13 \mathrm{mg} / \mathrm{l}$.

After treatment for at least 48 hours, the plasma concentrations in five infants were determined immediately before and at one and two hours after a suppository, to check for variability in concentrations at different times after a dose. In these same infants the half life of theophylline was calculated from concentrations 12 and 36 hours after stopping treatment.

Six infants had $\mathrm{PaCO}_{2}$ values recorded before and after treatment with aminophylline and three other babies had continuous transcutaneous $\mathrm{CO}_{2}$ recordings, linked to a computer based monitoring system, ${ }^{8}$ over the period that treatment was started.

All side effects related to aminophylline were noted.

\section{Results}

The relation between plasma theophylline concentrations and dose for the retrospective analyses of the hospital notes of 40 infants is shown in Fig. 1. Concentrations while on different dosages were determined in six babies, and in each of these the correlation coefficient for plasma concentration and dose was between 0.76 and 0.95 .

After the intravenous and rectal loading doses, maximum concentrations were achieved by two hours. The Table shows the mean plasma concentrations and numbers of apnoeic episodes, at two, 24, and 48 hours after starting treatment with aminophylline for each group.

In the groups (b) and (c), who received a loading dose, similar therapeutic concentrations were obtained by two hours, with steady concentrations and maximum effect achieved within 24 hours. In group (a) with no loading dose, the steady state and maximum therapeutic effect were still not obtained by 48 hours.

After treatment for at least 48 hours with a particular dose, there were no significant differences between the plasma concentrations taken at varying

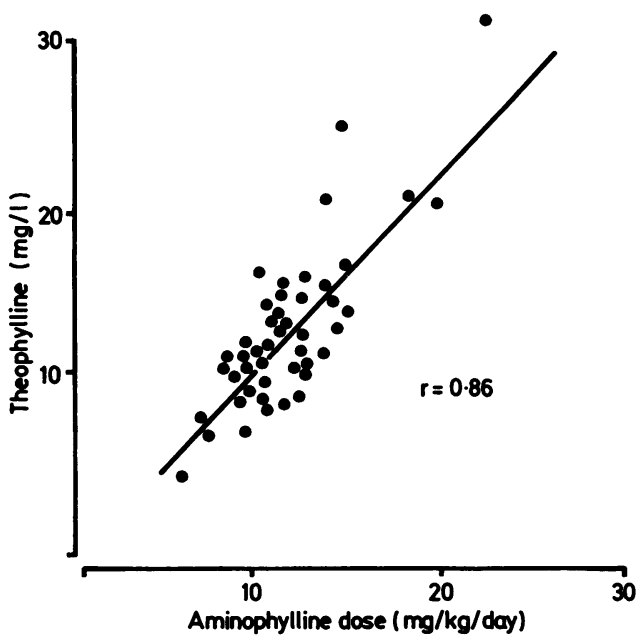

Fig. 1 Relation between plasma concentration of theophylline $(\mathrm{mg} / \mathrm{l})$ and dose $(\mathrm{mg} / \mathrm{kg} / \mathrm{d})$.

times after a dose. The half lives calculated from concentrations after treatment ranged from 23 to 37 hours.

Figure 2 shows the effect of aminophylline on $\mathrm{PaCO}_{2}$ values in four infants who responded to treatment and in two who showed no reduction in apnoeic episodes despite therapeutic blood concentrations. Continuous monitoring of transcutaneous $\mathrm{PCO}_{2}$ showed similar changes in transcutaneous $\mathrm{PCO}_{2}$ after treatment with theophylline.

Toxic effects were recorded in 14 infants. These were related to the plasma concentrations and were not found at concentrations less than $14 \mathrm{mg} / \mathrm{l}$. Twelve developed a tachycardia (greater than 170/ minute), six had glycosuria, and one infant became hyponatraemic. In two patients increased jitteriness and fits were recorded with plasma concentrations of 14.5 and $17 \mathrm{mg} / \mathrm{l}$.

An increase in basal heart rate occurred in all treated infants, and the rise correlated significantly

Table Relation between plasma concentration of theophylline at 2, 24, and 48 hours after starting treatment, with and without loading doses, and the number of apnoeic episodes (values, mean (SD))

\begin{tabular}{|c|c|c|c|c|c|c|c|c|c|}
\hline \multirow{4}{*}{$\begin{array}{l}\text { Loading dose } \\
\text { Concentration }(\mathrm{mg} / \mathrm{l}) \\
\text { Apnoeic episodes }\end{array}$} & \multicolumn{9}{|c|}{ Time after loading dose } \\
\hline & \multicolumn{3}{|l|}{2 hours } & \multicolumn{3}{|l|}{24 hours } & \multicolumn{3}{|l|}{48 hours } \\
\hline & None & $\begin{array}{l}p r \\
7.81(1.84)\end{array}$ & $\begin{array}{l}i v \\
7 \cdot 73(2 \cdot 26)\end{array}$ & $\begin{array}{l}\text { None } \\
5.81(1.44)\end{array}$ & $\begin{array}{l}p r \\
11 \cdot 19(2 \cdot 46)\end{array}$ & $\begin{array}{l}\text { iv } \\
10.73(2.09)\end{array}$ & $\begin{array}{l}\text { None } \\
10 \cdot 16(1 \cdot 38)\end{array}$ & $\begin{array}{l}p r \\
12.42(2 \cdot 08)\end{array}$ & $\begin{array}{l}\text { iv } \\
12.44(1.56)\end{array}$ \\
\hline & $0.51(0.29)$ & $0.49(0.43)$ & $0.51(0.20)$ & $0.31(0.37)$ & $0 \cdot 09(0 \cdot 10)$ & $0 \cdot 15(0 \cdot 10)$ & $0 \cdot 15(0 \cdot 17)$ & $0.06(0.06)$ & $0 \cdot 10(0.09)$ \\
\hline
\end{tabular}

$\mathrm{pr}=$ per rectum; iv=intravenously.

${ }^{*}$ pr and iv $v$ none, $\mathrm{P}<0.01$. 


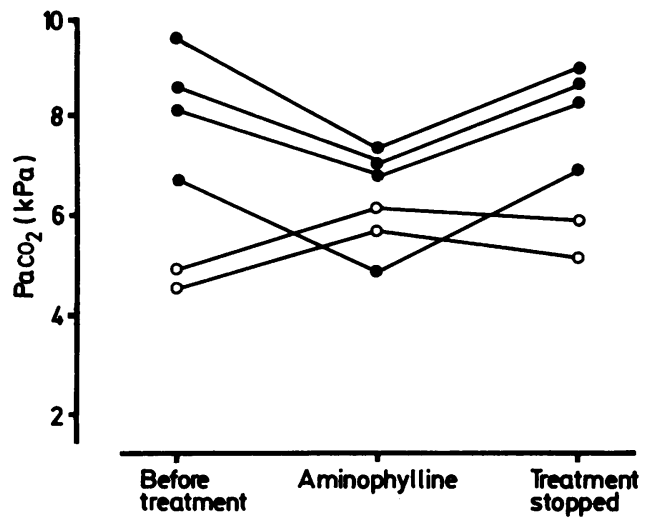

Fig. 2 Effect of aminophylline on $\mathrm{Paco}_{2}$ in 4 infants with apnoea who responded clinically (-O) and 2 infants with no clinical response $(\mathrm{O}-\mathrm{O})$.

Conversion-SI to traditional units: $1 \mathrm{kPa} \approx 7.52 \mathrm{mmHg}$.

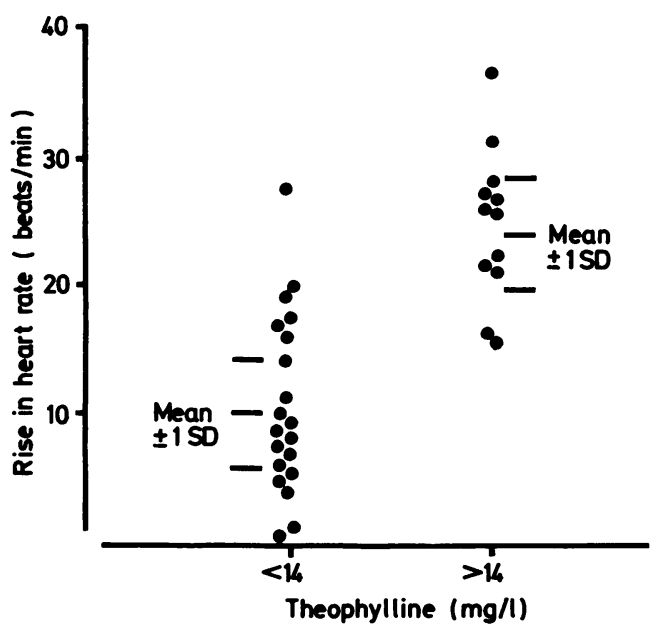

Fig. 3 The rise in heart rate with plasma theophylline concentration at 'therapeutic' and 'toxic' blood values.

with the concentration of theophylline $(r=0.65$ $P<0.05)$. A rise of greater than 20 beats/minute was seen in 12 of 14 infants with concentrations greater than $14 \mathrm{mg} / \mathrm{l}$, but in only one of 20 with a concentration less than $14 \mathrm{mg} / \mathrm{l}$ (Fig. 3).

No local side effects of the suppositories were noticed.

\section{Discussion}

Aminophylline suppositories proved an effective and safe means of administering theophylline to preterm neonates. The absorption was rapid, with therapeutic concentrations achieved within two hours of a loading dose of $10 \mathrm{mg} / \mathrm{kg}$. The correlation of plasma concentrations and dose was much better than that found in older children and adults, and possibly reflects a more controlled method of administration.

One of the major problems with suppositories is the difficulty in tailoring the dose to the needs of the individual. In most infants, therapeutic concentrations were maintained using $10 \mathrm{mg} / \mathrm{kg} /$ day and this dose was achieved with a combination of 3 and $5 \mathrm{mg}$ suppositories given three or four times a day. The long half life of theophylline in preterm infants means that even if given eight hourly, there will be very little change in concentration between doses. Good concentrations and response were achieved by a twice daily suppository in two infants. The manufacturers will supply suppositories of any required strength.

Theophylline improves respiratory drive, probably by increasing the sensitivity of the respiratory centre to $\mathrm{CO}_{2}{ }^{9}$ This increase in respiratory drive is shown by the reduction in $\mathrm{PCO}_{2}$ after treatment.

All preterm infants being treated with aminophylline should have the plasma concentration determined regularly for therapeutic monitoring. Even in the best centres, however, there can be a substantial delay in obtaining results from the laboratory. An increase in basal heart rate greater than 20 beats/ minute is an indication that the plasma concentration may be in the toxic range.

Aminophylline suppositories used in the management of apnoea of prematurity are as effective as, and a safe and convenient alternative to, the intravenous preparation.

We thank the nursing and medical staff on the Neonatal Unit for care and cooperation in managing these small infants and Mrs S Garrett, Mrs J Lyon, and Mrs V Williams for secretarial help.

\section{References}

${ }^{1}$ Kuzemko JA, Paala J. Apnoeic attacks in the newborn treated with aminophylline. Arch Dis Child 1973;48:404-6.

2 Shannon DC, Gotay F, Stein IM, et al. Prevention of apnoea and bradycardia in low birthweight infants. Pediatrics 1975;55:589-94.

3 Jones RAK, Baillie E. Dosage schedule for intravenous aminophylline in apnoea of prematurity, based on pharmokinetic studies. Arch Dis Child 1979;54:190-3.

4 Aranda JV, Sitar DS, Parsons WD, Loughnan PM, Neims AH. Pharmacokinetic aspects of theophylline in premature newborns. N Engl J Med 1976;295:413-6.

5 Rounds VJ. Aminophylline poisoning. Pediatrics 1954;14: 528-31.

6 Nolke AC. Severe toxic effects of aminophylline and theophylline suppositories in children. JAMA 1956;161:693-7.

${ }^{7}$ Bednarek FJ, Roloff DW. Treatment of apnoea of prematurity with aminophylline. Pediatrics 1976;58:335-9. 
${ }^{\gamma}$ Bass CA, Smith JS, Ducker DA. The use of a computer linked monitoring system for the continuous collection of physiological and environmental data from neonates undergoing intensive care. In: Rolfe $\mathrm{P}$, ed. Proceedings of 2nd International Conference on Fetal and Neonatal Physiological Measurements. London: Butterworths Scientific, 1985.
9 Davi MJ, Sankaran K, Simmons KJ, Simons FER, Seshia MM, Rigatto H. Physiologic changes induced by theophylline in the treatment of apnoea in preterm infants. J Pediatr 1978;92:91-5.

Correspondence to Dr N McIntosh, Neonatal Unit, St George's Hospital, London SW17 0QT. 